\title{
CON EL SUDOR DE TU FRENTE. TEORÍA Y FUENTES DOCUMENTALES PARA EL ESTUDIO DE LOS SALARIOS AGRÍCOLAS EN MÉXICO (SIGLOS XVI-XIX)
}

\author{
Sergio Valerio Ulloa*
}

ENTRE CLÁSICOS Y MARGINALISTAS:

EL DEBATE TEÓRICO SOBRE LOS SALARIOS

A

ntes de sumergirnos en el mar de documentos de los archivos históricos, tenemos que proveernos de una brújula conceptual que nos oriente en la búsqueda, si lo que pretendemos encontrar son documentos que nos den información sobre los salarios, lo primero que debe quedar claro es qué entendemos por el término salario.

Cuando Adán fue expulsado del Paraíso, Yahvé lo sentenció a comer el pan con el sudor de su frente. Desde entonces Adán y su descendencia tuvieron que trabajar para obtener sus alimentos de la tierra, que se convirtió en maldita por su desobediencia, dándole espinas y abrojos. Sin embargo, Yahvé no mencionó para nada que tenía que recibir por ello un salario que fuera el precio de dicho sudor. El trabajo como actividad productiva creadora de riqueza y de satisfactores para el consumo ha estado presente a lo largo de la historia humana, excepto en los tiempos en que Adán y Eva vivian en el Paraíso, cuando sólo tenían que estirar la mano para comer de los frutos de los árboles, según el pasaje conocido de la Biblia. ${ }^{1}$ Tanto el dinero, como las mercancías y el trabajo asalariado son categorías históricas que, aunque tienen una historia muy antigua, sólo ocupan un lugar primordial en la sociedad capitalista contemporánea. ${ }^{2}$

* Universidad de Guadalajara.

${ }^{1}$ Génesis, 3: 17-19.

${ }^{2}$ Marx, Introducción, 1980, pp. 61-66. 
En 1776, Adam Smith consideraba que "el salario era la recompensa justa o natural al producto del trabajo, por tanto esta remuneración en dinero era su precio". ${ }^{3}$ El nivel mínimo de este salario en las ocupaciones de menor categoría, para este autor, debería permitir al trabajador vivir de su trabajo y mantenerlo a él y a su familia. ${ }^{4}$ Smith pensaba que el precio del trabajo era una constante, no así el precio de los productos que el trabajador podía adquirir para su manutención y consumo con su salario. De esta manera, en la temporada en que los productos de consumo tenían precios altos, el trabajador podía adquirir una cantidad menor de bienes para su consumo familiar con su salario, mientras que en épocas de precios bajos, el trabajador podía adquirir una cantidad mayor de productos de consumo con el mismo salario. ${ }^{5}$

Posteriormente, en 1817, David Ricardo sostenía que la mano de obra, al igual que las demás cosas que se compran y se venden, tiene su precio natural y su precio de mercado. Ricardo entendía por precio natural de la mano de obra, el precio necesario que permitía a los trabajadores perpetuar su raza, sin incremento ni disminución. Esto no dependía de la cantidad de dinero que podía percibir el trabajador por concepto de salarios, sino de la cantidad de alimentos, productos necesarios y comodidades que por costumbre disfrutaba el trabajador, adquiriéndolos con dinero. ${ }^{6}$

Por otra parte, el precio de mercado de la mano de obra, según Ricardo, era el precio que realmente se pagaba por ella, según el libre juego de la oferta y la demanda, de tal manera que la mano de obra era costosa cuando escaseaba y barata cuando abundaba. Sin embargo, Ricardo sostenía que a pesar de que el precio de mercado de la mano de obra se desviara por arriba o por debajo de su precio natural, la influencia del libre juego de las fuerzas del mercado tendería a situar a ambos precios al mismo nivel a un plazo más o menos largo. ${ }^{7}$ De esta manera, los teóricos de la economía clásica llegaron a la conclusión de que en la sociedad capitalista el salario del obrero se manifiesta como el precio del trabajo, como una determinada cantidad de dinero que se paga por determinada cantidad de trabajo. Por lo tanto, el salario es la expresión dineraria del valor del trabajo a la cual se le denomina precio necesario o natural del trabajo. ${ }^{8}$

En gran parte, la validez de estos planteamientos sobre los salarios se apoyaba en la famosa ley malthusiana de la población que tan amplia-

${ }^{3}$ Smith, Investigación, 1958, p. 63.

${ }^{4}$ Ibid., p. 66.

${ }^{5}$ Ibid, p. 34.

${ }^{6}$ Ricardo, Principios, 1959, p. 71.

${ }^{7}$ Ibid., p. 72.

${ }^{8}$ Marx, Capital, 1975, t. 1, vol. 2, p. 651. 
mente aceptaban los economistas y otros hombres de ciencia a principios del siglo XIX. Esto implicaba que la oferta de mano de obra podía aumentar indefinidamente si el precio que por ella se ofrecía subía por encima de cierto nivel, entonces los obreros tendrían familias más numerosas y la oferta misma aumentaría. Este aumento provocaría una mayor competencia para ocupar los puestos disponibles, lo cual daría como resultado inevitablemente una caída de los salarios. Por el contrario, si los salarios cayeran por debajo del nivel de subsistencia, la población disminuiría paulatina o drásticamente, lo que se traduciría como una reducción de la oferta de mano de obra durante la siguiente generación, y la competencia entre los patrones, provocada por la disminución de trabajadores, elevaría nuevamente los salarios, de tal manera que volverían a situarse en el punto de equilibrio. ${ }^{9}$

Karl Marx, quien no estaba de acuerdo con esta ley malthusiana de la población, hizo una fina distinción entre lo que es el trabajo como producto terminado, objetivado, de una determinada actividad humana y lo que es el trabajo como la actividad humana de producir o hacer algo, trabajo vivo. Decía Marx en 1867 lo siguiente:

En el mercado, lo que se contrapone directamente al poseedor de dinero no es en realidad el trabajo sino el obrero. Lo que vende este último es su fuerza de trabajo. No bien comienza efectivamente su trabajo, éste ha cesado ya de pertenecer al obrero, quien por tanto ya no puede venderlo. El trabajo es la sustancia y la medida inmanente de los valores, pero él mismo no tiene valor alguno. ${ }^{10}$

Esta doble acepción de la palabra trabajo como trabajo objetivado y trabajo vivo o subjetivo es lo que llevó a cierta ambigüedad a los planteamientos de Smith y de Ricardo, pues cuando Smith dice que el salario es la recompensa justa al producto del trabajo, se entiende literalmente que la cantidad de dinero que se le paga al trabajador es igual al precio de los productos elaborados por el obrero mediante su actividad productiva, lo cual está muy lejos de ser cierto, pues el salario del trabajador nunca es igual al precio de los productos que su actividad genera. A lo que se refieren en realidad Smith y Ricardo con el concepto de valor del trabajo no es al valor de los objetos producidos por el obrero, sino al valor de la fuerza de trabajo que existe en la personalidad del obrero, a la capacidad para transformar las cosas, a la actividad enfocada a un fin productivo. De esta manera, según Marx, el valor y el precio de la fuerza de trabajo se presentan en su forma transmutada como salario. ${ }^{11}$

${ }^{9}$ Dobb, Salarios, 1941, pp. 82-83.

${ }^{10}$ Marx, Capital, 1975, t. I, vol. 2, p. 653.

${ }^{11}$ Ibid., pp. 655-656. 
Marx sostenía que la forma del salario ocultaba la división entre el trabajo necesario y el plustrabajo de los que estaba compuesta la jornada laboral del obrero, haciendo parecer como si todo el producto de la fuerza de trabajo fuera pagado. El capitalista, según Marx, siempre hacía funcionar la fuerza de trabajo durante más tiempo que el necesario para que se reprodujera el valor de la misma. El valor de la fuerza de trabajo, según este autor, estaba determinado por el valor de los medios de subsistencia que habitualmente necesitaba el obrero medio. ${ }^{12}$

Marx desarrolló una amplia explicación de la relación variable entre la parte de la jornada laboral destinada a reproducir el valor de la fuerza de trabajo, y la parte de la jornada laboral donde el trabajador generaba plusvalor, el cual era expropiado al obrero por el capitalista, a dicha relación Marx le dio el nombre de tasa de plusvalía, que en sentido estricto era un índice del nivel de explotación de la fuerza de trabajo por parte del capitalista. ${ }^{13}$

Lo común en los planteamientos teóricos de Smith, Ricardo y Marx es que tratan de explicar el valor de las cosas en función de la idea de que lo único que genera valor es el trabajo, por tanto las cosas valen según el tiempo de trabajo incorporado en ellas, y la fuerza de trabajo no está exenta de este planteamiento, pues el salario que recibe el obrero en dinero por su fuerza de trabajo es igual al valor de los medios de subsistencia que consume el obrero y su familia de manera constante, reproduciendo así sus condiciones de vida como individuo y como clase social, lo cual es un planteamiento que explica el salario desde el costo de producción o desde la oferta del trabajo. ${ }^{14}$

A fines del siglo XIX, y en oposición al planteamiento anterior, surgió la teoría marginalista que puso énfasis en la demanda y el consumo final, poniendo así el acento sobre la capacidad de lo que emergía de la línea de producción para contribuir a la satisfacción de los deseos, urgencias y necesidades de los consumidores. Ello derivó en un prejuicio individualista o atomístico del pensamiento económico moderno que condujo a la preocupación por el análisis microeconómico de la conducta y la acción individuales en el mercado y en el arraigamiento de las generalizaciones económicas de esos microfenómenos. Para los autores marginalistas como Jevons, Wieser, J. B. Clark, Wicksel, León Walras, Carl Manger, Vilfredo Pareto, Alfred Marshal y Joseph Schumpeter, el valor de las cosas dependía de su utilidad y no del trabajo incorporado en ellas. En consecuencia desarrollaron el concepto de utilidad marginal, el cual consiste en la

${ }^{12}$ Ibid., p. 629.

${ }^{13}$ Ibid., t. I.

${ }^{14}$ Dobb, Salarios, 1941, pp. 82-87. 
aplicación del cálculo diferencial a los incrementos marginales de utilidad o de la satisfacción que proporciona un bien al consumidor. ${ }^{15}$

Los economistas de esta época trataban de explicar el precio de una mercancía en función de la utilidad extra o satisfacción de los consumidores proporcionada por la unidad marginal o final de una oferta determinada. Por ejemplo: dada una oferta de $x$ kilos de trigo, el precio de un kilo (el último vendido) mediría la utilidad de los $x$ kilos para cualquiera de sus compradores. ${ }^{16}$ De esta manera, el valor natural de los bienes se estimaba simplemente de acuerdo con su utilidad marginal.

Esta teoría sobre el valor de las cosas ponía énfasis en la demanda y en la psicología individualista, el placer y la pena, el gusto o el rechazo del consumidor. Parecía deducirse de esto que el precio de la fuerza de trabajo podría explicarse en una forma similar por su utilidad marginal para algún comprador de ella, por ejemplo, el empresario capitalista. Pero el trabajo no satisfacía directamente las necesidades de los consumidores, sino que lo hacía de un modo indirecto, obteniendo un producto. De ahí que, dada cierta oferta de mano de obra, su precio se consideraba como determinado por el producto extra obtenido con el trabajo adicional de la unidad marginal de esa oferta. ${ }^{17}$

Para el empresario capitalista, el valor de la fuerza de trabajo consistía simplemente en el producto que le generaba, es decir, el precio de la fuerza de trabajo estaba en función de la productividad marginal del trabajo, esto es, de la última unidad de trabajo incorporada en proceso productivo. Al respecto, Schumpeter decía lo siguiente:

El valor de los bienes de producción es, en contraste con los bienes de consumo, un "valor de rendimientos", o bien "valor de productividad". A la utilidad marginal de los bienes de consumo corresponde el uso marginal productivo de los de producción, o su productividad marginal, para emplear el término común, la importancia de una unidad individual de los servicios de la tierra o trabajo, está dada por la productividad marginal de dichos elementos de la producción, que debe definirse, por tanto, como el valor de la unidad menos importante del producto ya obtenido con la ayuda de una unidad de un stock dado de los servicios de la tierra o el trabajo. Este valor indica la parte que corresponde a cada servicio total y, así, puede denominarse en un sentido definido el "producto" de un servicio de trabajo o tierra [...] Diremos también en este sentido que los precios de los servicios de la tierra y del trabajo en una economía de cambio, o sea rentas y salarios, se determinan por la productividad marginal de la tierra y el trabajo, y que a causa de ello puede decirse que en libre competencia, el terrateniente y el obrero perciben el producto de sus medios de producción. ${ }^{18}$

${ }^{15}$ Dobb, Teorías, 1982, pp. 185-230.

${ }^{16}$ Dobb, Salarios, 1941, p. 92.

${ }^{17}$ Ibid.

${ }^{18}$ Schumpeter, Teoría, 1944, pp. 37-38. 
Según los marginalistas, el valor de la fuerza de trabajo está en función de su productividad marginal, algo parecido a lo que decía Smith cuando aseguraba que el salario era la recompensa justa o natural al producto del trabajo. ${ }^{19}$ Para los marginalistas, el salario es igual a lo que produce el último trabajador incorporado al proceso productivo, nada tiene que ver en la determinación de los salarios el costo de los productos que consume el obrero para la subsistencia de él y de su familia, contrariamente a lo que también sostenía Smtih de que "el hombre ha de vivir de su trabajo y los salarios han de ser, por lo menos, lo suficientemente elevados para mantenerlo a él y a su familia". ${ }^{20}$ Conseguir los productos de subsistencia es, para los marginalistas, un asunto exclusivo del obrero que concurre al mercado para comprar lo que pueda con su salario, si le alcanza o no para vivir, ya no es culpa del patrón, quien pagó el precio justo de la fuerza de trabajo de acuerdo con la productividad de aquél.

Así pues, aunque las teorías expuestas anteriormente difieren en los factores determinantes del valor o del precio del trabajo o de la fuerza de trabajo, todas coinciden en que el salario es el precio de ésta, pero sólo Smith, Ricardo y Marx aclaran que el salario, entendido como simple precio de mercado de la fuerza laboral en abstracto es un concepto de la era capitalista. ${ }^{21}$ Ello supone, según Marx, un proceso previo al modo de producción capitalista que es la acumulación originaria de capital, o una "acumulación previa", en palabras de Smith, ${ }^{22}$ en el cual se forma, por un lado, la clase capitalista, dueña del capital y de los medios de producción; y, por otro lado, la clase de trabajadores libres y asalariados, despojados de todo medio de producción sin otra cosa que vender que su fuerza de trabajo como mercancía, pero a la vez dueños de su persona con la capacidad para ofrecerla al capitalista por un periodo determinado. ${ }^{23}$ Por el contrario, los teóricos marginalistas sostienen que sus descubrimientos sobre la productividad marginal del salario y la utilidad marginal de los bienes de consumo, y en general sus modelos económicos, son casi leyes naturales válidas para cualquier tipo de sociedad sin importar el periodo histórico ni el lugar. ${ }^{24}$

Concluyamos este largo apartado diciendo que el concepto moderno de salario se refiere a una forma específica de pago de la fuerza de

${ }^{19}$ Smith, Investigación, 1958, p. 63.

${ }^{20}$ Ibid, p. 66.

${ }^{21}$ Ibid, pp. 63-64; Ricardo, Principios, 1959, pp. 10-11; Marx, Capital, 1975, t. I, vol. 3, pp. 891-954.

${ }_{22}$ Smith, Investigación, 1958, p. 64.

${ }^{23}$ Marx, Capital, 1975, t. I, vol. 3, pp. 891-954.

${ }^{24}$ Dobb, Salarios, 1941, p. 93, y Teorías, 1982, pp. 185-230. 
trabajo por parte del capitalista, esta forma implica forzosa y necesariamente el pago en dinero, y supone que el obrero no posee los medios ni las condiciones para producir su propios medios de vida de forma independiente, es decir, no tiene tierras, ni herramientas propias, ni talleres, ni capitales de los cuales disponer para trabajar por su propia cuenta y obtener productos que pueda consumir él mismo o vender en el mercado e intercambiarlos por productos que posteriormente vaya a consumir. La única manera para que el obrero asalariado del capitalismo pueda obtener los medios de vida y de consumo necesarios para su subsistencia, es vender por cierta cantidad de dinero y durante determinado lapso su fuerza de trabajo, como cualquier otra mercancía y de manera "formalmente libre". Transacción que sí puede hacer porque el obrero en la sociedad capitalista es jurídicamente libre y dueño de su propia persona. Con este dinero, el trabajador concurre al mercado de bienes de consumo y obtiene, mediante la compra, los productos necesarios para el consumo de él y de su familia. Necesariamente todos los ingresos del obrero tienen la forma de dinero, ya que el modo de producción capitalista así lo impone en todos los intercambios de productos, en todas las relaciones sociales de producción y en todos lo cálculos de las empresas y empresarios capitalistas.

\section{SALARIOS AGRÍCOLAS DURANTE LA ÉPOCA COLONIAL Y EL SIGLO XIX EN MÉXICO}

El concepto moderno de salario tal como lo hemos expuesto hasta aquí no puede aplicarse en sentido estricto a las formas en que se contrataba o pagaba a la gran mayoría de los trabajadores del campo durante la época colonial y durante el siglo XIX en México, el mismo término no aparece tal cual lo entendemos ahora en los documentos de la época. Sin embargo, el concepto moderno de salario nos sirve de parámetro para explicar las formas precapitalistas de la retribución del trabajo, destacando su singularidad y sus diferencias con respecto a la forma moderna del salario en la sociedad capitalista. Por ello podemos afirmar que la retribución del trabajo implicaba en cada periodo histórico un determinado tipo de relaciones sociales y de producción, unas determinadas condiciones de vida, costumbres y cultura; y un determinado marco jurídico, político e ideológico.

En relación con esto Marx señalaba que las categorías que expresan las condiciones y la organización de la sociedad burguesa, por ser las más complejas y desarrolladas, permitían comprender la organización y las 
relaciones de producción de todas las formas de sociedad pasadas, sobre cuyas ruinas y elementos ella fue edificada. ${ }^{25}$

De tal manera que no podemos hacer un análisis retrospectivo de los salarios en la larga duración, como si fuera la misma cosa, sin forzar el concepto y caer en anacronismos. Aunque sea muy tentador, habrá que renunciar a hacer la curva de los salarios en el largo plazo, pues los salarios de hoy no son ni significan lo mismo que los salarios de hace 100, 200 o 300 años. En primer lugar, porque el salario del obrero moderno representa la totalidad de los ingresos del mismo, mientras que el salario de los peones y jornaleros agrícolas anteriores al siglo Xx no incluía todos los bienes y servicios consumidos por ellos. Por otra parte, la elaboración de una curva de salarios en el largo plazo es imposible porque no se cuenta con información estadística suficiente, al menos hasta inicios del siglo Xx, para construir series más o menos continuas y confiables de salarios y precios que nos den una idea aproximada del nivel de vida de los trabajadores o el índice de explotación de la fuerza de trabajo en el largo plazo.

Ello no quiere decir que se deba renunciar a hacer historia cuantitativa y análisis estadístico sobre los salarios en México, sino que se debe explicar claramente de dónde surgieron y cómo se elaboraron las series cuantitativas y estadísticas, es decir, hay que hacer una profunda crítica a las fuentes y, sobre todo, reconocer y advertir al lector los límites y los alcances de dicha información. Habrá que contentarse con el corto y mediano plazo donde la información al alcance es más significativa, particularmente el segundo, que es el propio de la coyuntura como señalaba Braudel ${ }^{26}$ ya que se puede entrecruzar o complementar con otra información relacionada con los salarios como los precios de los productos de consumo popular, las condiciones de vida de los trabajadores y su relación con la cultura material y espiritual particulares de cada región o comunidad, las formas específicas en que se contrataba o explotaba el trabajo, el crecimiento de una determinada actividad económica y el nivel de desarrollo de la tecnología o la integración de ciertos mercados.

Por otra parte, es más o menos fácil entender por qué no hay fuentes que nos hablen de los salarios en la época prehispánica, ya que la respuesta es obvia: dentro de las sociedades indígenas prehispánicas no hubo algo que se asemejara al trabajo asalariado, no existió una economía monetizada y la expropiación de los excedentes por parte de los pueblos y grupos dominantes a los dominados se dio con base en el tributo en especie y en trabajo. ${ }^{27}$ Esta forma de explotación del trabajo de las comu-

${ }^{25}$ Marx, Introducción, 1980, pp. 62-63.

${ }^{26}$ Braudel, Historia, 1989, pp. 60-106.

${ }^{27}$ Carrasco, "Economía", 1980, pp. 29-32; López y López, Pasado, 2001, pp. 218-239. 
nidades indias fue continuada por los españoles durante los primeros 50 años de la conquista a través de la encomienda, de tal manera que los indios trabajaban para los españoles sin que mediara el pago de salarios. $^{28}$

Durante todo el siglo XVI y la primera parte del XVII predominaron dos sistemas compulsivos para retener la mano de obra en las actividades productivas que les interesaban a los españoles, uno de ellos, como ya se mencionó, era la encomienda, el otro fue el repartimiento. Además los conquistadores contaron con otras dos fuentes de mano de obra forzada: una proveía de esclavos indios habidos por derecho de guerra, y la otra, proveía de esclavos negros traídos de África. ${ }^{29}$ Durante los primeros años de la colonia, la corona española trató de crear una fuerza de trabajo que tuviera libertad para escoger sus propias tareas y fuera adecuadamente recompensada por su trabajo con un salario. Esta forma de contratación de la mano de obra nunca surgió en el periodo colonial, pero los intentos por constituirla por parte de las autoridades españolas propiciaron grandes cambios en las relaciones entre patronos y trabajadores a lo largo de estos dos primeros siglos de vida colonial. ${ }^{30}$

Para lograr lo anterior, la corona resolvió, en primer lugar, eliminar el trabajo no recompensado de las listas de tributo, se otorgó la libertad a los indios esclavos y en 1549 una real cédula y otras órdenes consecutivas prohibieron el servicio personal que daban los indios a los encomenderos, mandando que en adelante los servicios y el tributo se pagaran en dinero o en especie; propusieron un sistema rotativo de alquiler, con trabajo moderado, pocas horas, distancias limitadas y salarios. Las leyes debían aplicarse en la encomienda y en el corregimiento, e implicaban que la coacción era innecesaria y que los indígenas podían trabajar voluntariamente si se aportaba un salario suficiente..$^{31}$

Sin embargo, la población indígena comenzó a experimentar un descenso rápido debido a las epidemias, la guerra, el exterminio, los trabajos forzados y el desgano vital, ${ }^{32}$ lo que provocó una alarmante escasez de mano de obra indígena; los encomenderos se vieron seriamente afectados en el monto de sus tributos, y los españoles no encomenderos reclamaban urgentemente mano de obra indígena para sus minas, haciendas y obrajes. Los indígenas que contaban con tierras en sus comunidades no veían incentivos ni motivos por los cuales voluntariamente debían ofrecer su mano de obra a los españoles, lo cual ponía en riesgo la eco-

\footnotetext{
${ }^{28}$ Moreno, "Siglo", 1977, vol. 2, pp. 1-81.

${ }^{29}$ Florescano, Origen, 1986, pp. 100-109.

${ }^{30}$ Gibson, Aztecas, 1981, p. 228.

${ }^{31}$ Ibid.

${ }^{32}$ Borah, Siglo, 1982, pp. 13-19.
} 
nomía de estos últimos, además de que la demanda de mano de obra indígena por parte de los españoles se hacía en las épocas en que los indios estaban más ocupados en sus propias parcelas. Ante esta situación, la política persuasiva de la corona española para que los indígenas se alquilaran voluntariamente en las labores del campo y de la ciudad a cambio de un salario fracasó, y se fortaleció el sistema compulsivo que beneficiaba y era necesario para los españoles. ${ }^{33}$

La solución a estos problemas fue el repartimiento o coatequil, institución que dominó el reclutamiento de trabajadores indígenas entre 1550 y 1630. Fue un sistema de trabajo racionado, rotativo, supuestamente de interés público o para utilidad pública, que afectaba tanto a los indígenas de encomienda como a los que no entraban dentro de la encomienda, y beneficiaba a una clase de patronos mucho más amplia de lo que había sido bajo la encomienda. En realidad, no se apegaba a las exigencias de la corona de pocas horas, tareas moderadas o trabajo voluntario por salario. Pero sujetó, por primera vez, los procedimientos laborales de la colonia al escrutinio administrativo y satisfizo, al menos temporalmente, las necesidades de los nuevos patronos coloniales. ${ }^{34}$

Los orígenes del repartimiento anteceden a las leyes de 1549, los principios de obligación y rotación, que eran esenciales al sistema, tenían precedentes en el trabajo anterior a la conquista y en los primeros años coloniales. Los españoles interesados en recibir indios de servicio para sus labranzas acudían a las autoridades virreinales y éstas les expedían un mandamiento que autorizaba a los jueces repartidores de los pueblos a darles los indios que necesitaban. En el repartimiento, como en el tributo, los gobiernos indígenas trataron de conservar las organizaciones indígenas existentes, de tal manera que eran las autoridades indígenas las que designaban cuáles indios y en qué momento debian ser ofrecidos para el repartimiento, siguiendo los procedimientos del coatequil indígena. De la población tributaria de cada pueblo se eximía de repartimiento a la quinta parte, con el fin de exceptuar del servicio a los caciques, principales, viejos, enfermos e impedidos. Del número restante se repartía 2 o $4 \%$ en tiempos normales y $10 \%$ cuando se debían hacer la escarda y la cosecha. El repartimiento se hacía en tandas semanarias, de manera que cada trabajador en promedio servía tres semanas al año, pero repartidas en plazos cuatrimestrales; sólo los solteros mayores de quince años servían cuatro semanas al año. Los indios debían ser bien tratados y únicamente debían ocuparse en las labores que se señalaban en el momento de hacer el repartimiento. A cambio de su trabajo recibían un

${ }^{33}$ Florescano, Origen, 1986, p. 101.

${ }^{34}$ Gibson, Aztecas, 1981, p. 229. 
jornal, que de 1575 a 1610 varió desde medio real hasta real y medio (un peso era igual a ocho reales). Además del jornal, los indios solían recibir raciones de alimentos más los gastos de ida al lugar de trabajo y los de vuelta a su comunidad. ${ }^{35}$

A través del repartimiento, los indios fueron llevados a trabajar a las minas, a las haciendas, a las estancias ganaderas, a las obras de construcción de casas particulares y obras públicas, a la construcción de caminos, puentes, iglesias y conventos, haciendo progresar a las distintas actividades económicas. Pero el repartimiento forzoso de la mano de obra indígena no satisfacía plenamente a los patronos españoles, porque era temporal, además de que con el descenso demográfico cada vez había menos indios que repartir, de tal manera que las obligaciones del repartimiento recaían con más frecuencias en los mismos indios y eran obligados a trabajar más tiempo fuera de sus comunidades. ${ }^{36}$ Por ello se buscaron otras formas para lograr retener a la mano de obra indígena dentro de las unidades productivas del campo y de la ciudad. Después de varios intentos, finalmente en 1633 se estableció de forma definitiva la prohibición de todos los repartimientos por parte de las autoridades virreinales. ${ }^{37}$

A pesar de que las leyes, órdenes y mandamientos reales establecían que el repartimiento de indios se hiciera sin violentarlos ni maltratarlos, el repartimiento no dejó de ser un sistema compulsivo de la fuerza de trabajo, los indios eran obligados a salir de sus comunidades por temporadas cortas, tres o cuatro semanas al año, para luego regresar a sus pueblos; el salario monetario, si es que se les pagaba, cubría sólo el trabajo realizado durante esas cortas temporadas, y el resto del año se la pasaban en sus comunidades atendiendo sus propias tierras y otras actividades económicas y sociales. No era pues un salario diario constante que cubriera las necesidades cotidianas de los indios, pues éstas eran cubiertas por las actividades agrícolas, ganaderas y artesanales desarrolladas dentro de su comunidad.

A fines del siglo XVI, la agricultura manejada por españoles progresaba continuamente en los valles de México, Toluca, Puebla, Tlaxcala, Oaxaca, Morelia, Guadalajara y en el norte minero. En estas zonas, las haciendas como grandes unidades territoriales dedicadas a la agricultura y a la ganadería comerciales se iban consolidando. Para sus propietarios, los ricos hacendados, el problema en esa época no era la tierra, pues la había en abundancia, ni los mercados, que se empezaron a formar y estaban creciendo, sino la disponibilidad de mano de obra suficiente y fija que

${ }^{35}$ Florescano, Origen, 1986, p. 102; Gibson, Aztecas, 1981, pp. 230-233.

${ }^{36}$ Florescano, Origen, 1986, pp. 102-103.

${ }^{37}$ Gibson, Aztecas, 1981, p. 240. 
asegurara el trabajo en las haciendas durante todo el año. El sistema de repartimiento funcionó temporalmente para llenar la necesidad de mano de obra en las haciendas agrícolas, pero no satisfacía plenamente sus necesidades porque era temporal y dependía del número de habitantes de los pueblos, el cual estaba en franca disminución por las epidemias, y porque finalmente dependía de la voluntad de las autoridades virreinales o de los jueces de repartimiento conceder o no a los indios. Cuando los pueblos indígenas dejaron de cumplir con sus cuotas de repartimiento, los hacendados quisieron asegurarse el servicio de trabajadores por medios independientes. ${ }^{38}$

A partir de entonces, los propietarios de las fincas agrícolas se esforzaron por arraigar permanentemente a los indios y sus familias en las tierras de la hacienda con el consecuente abandono de sus pueblos. Para ello, los propietarios agrícolas hacían contratos individuales que ligaban a los trabajadores indígenas al servicio privado. Dichos contratos consistían en adelantos en dinero o en ropa, o simplemente se los obligaba a permanecer en la finca por la fuerza, lo cual debilitaba a las comunidades indígenas que veían disminuir más el número de indios necesarios para las labores de la comunidad y para el repartimiento; ahora las obligaciones y el trabajo recaían en un menor número de indios de la comunidad, pero también, por otra parte, disminuían los tributos de los encomenderos. Los indios que aceptaron la oferta de los hacendados recibieron el nombre de gañanes, laboríos o naborios y fueron el origen de los peones acasillados de los siglos posteriores. ${ }^{39}$

El término peonaje ha sido asociado generalmente al sistema de adelantos y endeudamiento para retener por la fuerza y contra su voluntad a los trabajadores de las haciendas en el campo mexicano, siendo considerado un sistema injusto y cuasi esclavista, es decir, un esclavismo disfrazado porque no estaba permitido por las leyes, pero se daba en la realidad. ${ }^{40}$ Sin embargo, como señala Katz, ser peón no necesariamente significaba estar endeudado con la hacienda. El término peón significaba simplemente ser un trabajador, generalmente en la agricultura, pero también se aplicaba a los trabajadores en las minas; el término no implicaba automáticamente el endeudamiento o la residencia en una hacienda, lo cual no quiere decir que no haya habido peones endeudados y peones acasillados. ${ }^{41}$

Es indudable que el propietario de una hacienda buscaba por todos los medios contar con los trabajadores necesarios para las actividades

${ }^{38}$ Florescano, Origen, 1986, pp. 102-103; Gibson, Aztecas, 1981, p. 251.

${ }^{39}$ Florescano, Origen, 1986, p. 103.

${ }^{40}$ Nickel, Peonaje, 1997, pp. 11-12.

${ }^{41}$ Katz, Servidumbre, 1982, p. 14. 
agrícolas durante todo el año. Sin embargo, ello dependía de la abundancia o escasez de mano de obra disponible, según las propias condiciones demográficas de los pueblos indígenas y de acuerdo con los sistemas legales de sujeción y asignación de la mano de obra indígena en los primeros siglos de la colonia. Dada la incapacidad del repartimiento por abastecer de suficiente mano de obra a los hacendados, éstos trataron de retener a los trabajadores indígenas por medio de adelantos en dinero y en productos, incluso por la fuerza a pesar de que estaba prohibido; pero el endeudamiento por sí solo no es suficiente para explicar las razones que tenían los indios para abandonar sus comunidades y residir permanentemente en las haciendas.

La crisis demográfica había disminuido drásticamente el número de indios en las comunidades, de tal manera que las cargas tributarias y los servicios personales, así como las obligaciones del repartimiento recaían en mayor medida en un menor número de indios disponibles, lo que representaba una carga mayor para cada uno de los indígenas de la comunidad. Estas presiones hacían que los indígenas quisieran evitar sus obligaciones, huyendo de sus pueblos, y los hacendados les daban la posibilidad de no regresar quedándose a trabajar en las haciendas de forma permanente.

De tal manera, en su origen el peonaje se explica mejor por la desarticulación de la comunidad indígena y el proceso de aculturación intenso que sufrió la población del centro de México, que por lo atractivo de los salarios o de los adelantos en ropa y en dinero. Los indios que aceptaron vivir y trabajar en las haciendas de españoles a partir de 1580 fueron indios que ya habían perdido sus tierras o habían nacido sin ellas, indios recién liberados de la esclavitud $y$, sobre todo, indios que habían servido con anterioridad en las haciendas bajo el sistema de la encomienda o del repartimiento. Estos indios habían roto sus lazos con su comunidad ante las opciones que se les presentaban; el ser peón de una hacienda más que una pérdida era una ganancia, pues permanecer en la comunidad, ser indios sueltos o vagabundos, ir a trabajar a las minas o a los obrajes era para ellos mucho más gravoso que trabajar en una hacienda. ${ }^{42}$

Los adelantos en dinero o en especie y el nivel de endeudamiento eran, a finales del siglo XVI en el centro de México, un mecanismo de negociación entre el hacendado y los trabajadores indígenas. Los altos niveles de éstos reflejaban un poco la capacidad de regateo que tenían los indios para aceptar ir a trabajar a la hacienda, pero ello no quiere decir que no haya habido en algún momento el recurso de la fuerza para retener a los trabajadores indios, sino que en la mayor parte de los casos

${ }^{42}$ Florescano, Origen, 1986, pp. 106-107. 
eran las condiciones sociales y económicas que prevalecían en las comunidades las que obligaban a los indígenas a salir de ellas y ofrecer su mano de obra a los hacendados. Un trabajador indio inclinado a abandonar la hacienda en donde trabajaba, podía encontrar la ocasión de hacerlo a pesar de las deudas, así como cualquier indio podía evadir su deuda de tributo a un pueblo o su deuda privada a cualquier acreedor. ${ }^{43}$

De cualquier manera, los hacendados durante el siglo XVIII y XIX siguieron recurriendo al sistema de adelantos, enganche y endeudamiento para atraer a la mano de obra indígena situada en los pueblos cercanos, y no era la única forma de conseguir trabajadores para la hacienda. Las haciendas de finales del siglo XVIII y durante todo el XIX tenían cuatro clases de trabajadores: 1) los peones acasillados o gañanes, que en su mayoría eran trabajadores agrícolas, aunque también eran vaqueros, pastores o artesanos; 2) los trabajadores eventuales o temporales, que trabajaban las tierras por temporadas o por tareas; 3) los arrendatarios y 4) los medieros o aparceros. ${ }^{44}$ Cada una representaba una forma particular de relación económica con la hacienda o con su propietario.

Los peones acasillados vivían permanentemente en la hacienda, en casas pequeñas cercanas al casco de la hacienda, su ingreso provenía de cuatro formas distintas: 1) tenían una pequeña parcela o pejugal que les cedía el hacendado; 2) recibían una ración diaria de maíz y frijol, y a veces de otros bienes que les daban anualmente de las haciendas; 3) tenían el derecho de apacentar animales en tierras de la hacienda; y 4) recibían un salario en dinero que se les pagaba por cada día de trabajo en los campos del hacendado. Además tenían acceso al crédito que les otorgaba el hacendado mediante la tienda de raya. ${ }^{45}$ La cantidad de peones acasillados en las haciendas mexicanas variaba de una hacienda a otra, y de región a región, pero parece que el número de peones de residencia permanente constituía una minoría en la fuerza laboral de la mayoría de las haciendas mexicanas.

Los trabajadores eventuales o jornaleros temporales realizaban la mayor parte del trabajo y formaban un grupo mucho más complejo, mucho más difícil de describir y de precisar que el de los peones residentes, provenían de los pueblos indígenas libres y dueños de tierras, o podían ser pequeños propietarios que buscaban un ingreso complementario. Algunos provenían de aldeas cercanas a la hacienda y allí vivían, trabajaban durante el día y en la noche regresaban a sus pueblos, otros provenían de regiones más apartadas y tenían que vivir por temporadas

${ }^{43}$ Gibson, Aztecas, 1981, pp. 259-262.

${ }^{44}$ Katz, Servidumbre, 1982, pp. 15-16.

${ }^{45}$ Ibid. 
más o menos largas en la hacienda. Estos trabajadores recibían sólo su salario diario en dinero más su ración de maíz y de frijol. ${ }^{46}$

Los arrendatarios vivían permanentemente en tierras de la hacienda, aunque no necesariamente cerca de la casa principal, obtenían la parte más considerable de sus ingresos de las tierras que la hacienda ponía a su disposición. Sus terrenos eran mayores que los de los peones acasillados y tenían que pagar a la hacienda, en efectivo o en productos, por el uso de la tierra. Los arrendatarios podían alquilar desde una pequeña parcela hasta una gran extensión o un rancho entero, algunos cultivaban por sí mismos las tierras, mientras que otros contrataban trabajadores. ${ }^{47}$

Los convenios con los medieros o aparceros eran muy variables. Éstos vivían también en tierras de la hacienda o en aldeas cercanas, y la hacienda los proveía de tierras y el mediero las trabajaba con sus aperos y animales o, en caso de que no los tuviera, los rentaba a la hacienda. Al término de la cosecha, se repartía por mitad el producto de la misma entre el hacendado y el mediero; de la parte que le tocaba al mediero se debía pagar los adelantos en dinero o en especie que el hacendado le hubiera proporcionado al mediero al inicio del ciclo agrícola, más los préstamos y el crédito que hubiera solicitado en la tienda de raya, más la renta de aperos, carretas y bueyes que hubiera utilizado de la hacienda, y, por último, se le descontaban los utensilios que hubieran sido destruidos o los animales que pudieran haber muerto mientras los usaba el mediero en sus labores. De tal manera que la parte correspondiente al mediero se veía muy disminuida una vez realizadas las cuentas necesarias. ${ }^{48}$

Por consiguiente, sólo los peones acasillados y los jornaleros temporales recibían un pago en dinero al que se le denominaba salario, pero éste no constituía el total de los ingresos de los trabajadores. Si tomamos exclusivamente al salario monetario que recibían los peones agrícolas como un índice del nivel de vida de los trabajadores del campo mexicano de lo siglos XVIII y XIX vamos a llegar irremediablemente a conclusiones erróneas. $\mathrm{Al}$ respecto, y siguiendo a los economistas clásicos, Andrés Molina Enríquez decía lo siguiente en 1909 para la región del centro de México:

El salario o jornal, en todas partes del mundo, tiene como límite inferior el valor de lo que indispensablemente necesita para no morir de hambre, y como límite superior, el valor de lo que exige la oferta como compensación del trabajo; dentro de estos dos límites extremos, la función de la demanda determina el salario o jornal corriente. En la zona fundamental, el valor de lo que indispen-

\footnotetext{
${ }^{46}$ Ibid.

${ }^{47}$ Ibid., p. 17.

${ }^{48}$ Valerio, Historia, 2003, pp. 181-191.
} 
sablemente necesita un hombre para vivir, tiene que ser determinado por el valor del maíz y los demás artículos que le son complementarios, puesto que de este grano y de estos artículos, forzosamente tendrá que alimentarse y muy especialmente por el valor del maíz, que constituye la materia principal de su alimentación. ${ }^{49}$

Molina Enríquez tendría razón en establecer el mínimo del valor del salario en el maíz y otros productos como el trigo, el frijol, el chile y el pulque si el trabajador y su familia sólo necesitaran de alimentos para vivir, ${ }^{50}$ pero dentro del nivel de vida debe estar considerado el vestido, la vivienda, los gastos de educación y de salud, además de los gastos sociales y religiosos, según las necesidades y costumbres de la época. La afirmación de Florescano de que la "clave para conservar a los peones arraigados a la hacienda consistió en mantenerlos a un nivel de subsistencia mínima" ${ }^{51}$ carece de sentido. Hablar de altos y bajos salarios en términos muy generales no nos dice nada, lo mismo que no nos dice mucho hablar de altos y bajos precios si no contextualizamos de forma precisa la época y el lugar.

Lo primero que hay que considerar es que la mayor parte de los trabajadores agrícolas en el campo mexicano hasta principios del siglo $\mathrm{xX}$ no eran asalariados, de tal manera que si queremos estimar el nivel de vida mediante el salario pagado a los peones, estaremos dejando de lado a los campesinos de las comunidades indígenas que poseían tierras propias, a los arrendatarios y a los medieros. En segundo lugar, el nivel de los salarios y su relación con respecto a los precios de los bienes de consumo popular variaba mucho de una región a otra durante los siglos XVIII y XIX en el país. En tercer lugar, hay que tener en cuenta que el salario era sólo una parte del ingreso total de los peones; en el caso de los peones acasillados se debería contemplar como sus ingresos los bienes y servicios que recibían de la hacienda y que no estaban contabilizados como tales, como las raciones de maíz y frijol, la renta de una casa, la renta de una parcela, el derecho o permiso de apacentar y criar animales propios, el acceso al crédito de la tienda de raya, entre otros. En el caso de los peones temporales de debe contemplar que en la mayoría de los casos, eran habitantes de aldeas en donde tenían tierras que sembrar y cuyos productos formaban parte de sus ingresos familiares, además de que también recibían su ración diaria de maíz y de frijol.

Finalmente, aunque el peón sólo recibiera como ingreso su salario y la ración de maíz y frijol, se debe considerar que el maíz y el frijol que

${ }^{49}$ Molina, Grandes, 1985, p. 292.

${ }^{50}$ Ibid., p. 283.

${ }^{51}$ Florescano, Origen, 1986, p. 107. 
constituían la base de su alimentación se pagaban en especie y que el peón no necesitaba comprarlos en el mercado para su alimentación, de tal manera que el salario ya no se destinaba a comprar estos dos alimentos fundamentales, sino que servía para comprar otros productos como manta, café, sal, azúcar, huaraches o sombreros, los cuales no necesariamente entraban dentro del cálculo de los salarios mínimos. Por tal motivo, las variaciones en los precios del maíz y del frijol en el mercado nos dicen muy poco del nivel de consumo de los peones acasillados y de los jornaleros temporales, pues estos trabajadores no compraban en el mercado dichos productos. Al menos esto pasaba en las zonas donde las haciendas producían maíz y frijol de forma abundante, no así en las zonas donde las haciendas se dedicaban de forma principal a otros cultivos como caña de azúcar, trigo, henequén, ganado o algodón, en donde el hacendado tenía que comprar el maíz y el frijol y venderlos a los peones en la tienda de raya.

\section{FueNTES DOCUMENTALES DE LOS SALARIOS}

Las fuentes documentales para el análisis del sistema de repartimiento provienen de las mercedes y órdenes otorgadas por las autoridades virreinales a los patronos españoles ubicadas en el Archivo General de la Nación y en el Archivo General de Indias, y en la obra recopilada por Silvio Zavala y María Castelo, ${ }^{52}$ además de otras fuentes como los documentos referentes a la construcción de obras para el desagüe de la ciudad de México las cuales ocuparon principalmente indios de repartimiento. ${ }^{53}$ Moisés González Navarro también recopiló una serie de breves órdenes del presidente y los oidores de la Real Audiencia de Guadalajara dadas a los alcaldes y mandones de distintos pueblos de indios, y en las cuales se concedía el reparto de cierto número de indios para que trabajaran en las labores de los españoles peticionarios. Estos documentos se encuentran en los Libros de Gobierno del Archivo de Instrumentos Públicos de Guadalajara. ${ }^{54}$

La mayor parte de la documentación que contiene información sobre los salarios de los trabajadores agrícolas se refiere a la parte de los ingresos que tenía una forma monetaria. De esta manera se estima que, de 1550 a 1650, el salario diario de los peones varió de medio real $(0.0625$ pesos) hasta uno y medio reales ( 0.1875 pesos), mientras que de esta últi-

\footnotetext{
${ }^{52}$ Zavala y Castelo, Fuentes, 1939.

${ }^{53}$ Gibson, Aztecas, 1981, pp. 225-262.

${ }^{54}$ González, Repartimientos, 1977.
} 
ma fecha hasta finales del siglo XVIII se mantuvo entre uno y medio reales y dos reales y medio ( 0.3125 pesos), en tanto que la ración de maíz era de un almud (4.625 litros) durante los siglos XVI y XVII, y de un almud y medio (6.937 litros) y dos almudes (9.25) en el siglo XVIII, ${ }^{55}$ lo que supuestamente representaría un aumento en los salarios nominales, sin embargo, está en duda si realmente ello significó un mejoramiento en las condiciones de vida de los peones.

De la misma manera, las pocas estadísticas que existen para el siglo XIX refieren que los salarios en la agricultura durante el porfiriato subieron de 0.2177 a 0.4369 pesos corrientes, y que los salarios variaban de una zona a otra del país, siendo las zonas del norte y del Golfo donde se pagaban los salarios más altos y la zona centro donde se pagaban los más bajos. ${ }^{56}$ Vuelvo a insistir sobre esta falta de relevancia de lo alto y lo bajo de los salarios con respecto al nivel de vida de los trabajadores agrícolas, pues las zonas de más altos salarios como la del norte también eran la zonas de más altos precios, y el aumento de los salarios a lo largo del porfiriato también fue acompañado de un aumento general de los precios de los principales productos de consumo popular así como de una depreciación de la plata. ${ }^{57}$ Además de que, dada la estructura de la forma de contratación de la fuerza de trabajo en el campo mexicano, el salario, de forma aislada y exclusiva, nos dice muy poco sobre el nivel de vida de los trabajadores rurales.

Las fuentes de información globales sobre salarios para la primera mitad del siglo XIX en México son muy escasas, sólo a partir de la segunda mitad de este siglo se llevaron a cabo repetidas y extensas encuestas demográficas, sin embargo, la mayoría de ellas únicamente presentaban datos sumamente agregados y a la vez incompletos y poco confiables. ${ }^{58}$ Por ejemplo, las Estadísticas de la república mexicana publicadas por Emiliano Busto en tres volúmenes en 1880, se refieren al año fiscal 1877-1878, fueron compiladas a partir de informes entregados a la Secretaría de Hacienda por los jefes políticos, agentes de hacienda y colaboradores particulares procedentes de toda la república, y no indican datos por debajo del nivel distrital, esto es, de municipios, pueblos, haciendas y ranchos. La información que Busto recibió fue cuando mucho de una tercera parte de todos los distritos habidos en la república, y en donde no hubo información los datos simplemente fueron inventados por él..$^{59}$

\footnotetext{
${ }^{55}$ Ibid.

${ }^{56}$ Estadísticas, 1960, pp. 147-149.

${ }^{57}$ Velasco et al., Estado, 1988, pp. 286-312.

${ }^{58}$ Nickel, Peonaje, 1997, pp. 152-153.

${ }^{59}$ Coatsworth, Origenes, 1990, pp. 167-168.
} 
A pesar de todas las críticas que se le puedan hacer, es sólo a partir de las encuestas realizadas por Emiliano Busto que se cuenta con estadísticas relativamente en el ámbito a nivel distrital sobre salarios y precios, el problema es que no hay datos para niveles más bajos de agregación como municipios, haciendas, ranchos, rancherías o comunidades. Posteriormente, durante el porfiriato se mandó realizar censos similares en mayor cantidad y con un catálogo de preguntas más amplio. Hacia finales del siglo XIX y a principios del XX se estableció la estadística oficial a través de la Dirección General de Estadística, con la cual se iniciaba la fase moderna de los levantamientos estadísticos hasta las unidades administrativas más pequeñas. La estadística agraria estaba atendida por el Ministerio de Fomento, que en los años noventa encargó a una Comisión Mexicana para la Exposición de París de 1900, que elaborara la base para las presentaciones de las exposiciones mundiales del año de $1900 .^{60}$

El objetivo de las autoridades porfirianas con estos censos y su presentación en las exposiciones mundiales era captar el interés de los inversionistas extranjeros para México, por tal motivo se levantaron datos sobre diversos conceptos de la actividad agrícola como extensión y clases de terrenos, número de peones, monto de los salarios, maquinaria utilizada, producción agrícola y ganadera, entre otros. En algunos archivos comunitarios y gubernamentales, todavía se conservan los datos levantados en la estadística agraria, los cuales ya dan información particular para cada hacienda y rancho, y dan los agregados para cada municipio, departamento, distrito o cantón, y por estado. Estos documentos se han encontrado en los archivos municipales del Ayuntamiento de Puebla y Tepeaca en el estado de Puebla, en el Archivo Histórico de Sonora ${ }^{61}$ y en el Archivo Histórico de Jalisco. ${ }^{62}$

Por otra parte, la mayoría de la historiografía económica sobre el siglo XIX utiliza la información contenida en las Estadísticas económicas del porfiriato, elaboradas por el equipo que trabajó en la obra Historia moderna de México, en los volúmenes de la vida económica y las Estadísticas sociales del porfiriato publicadas por El Colegio de México en $1956 .{ }^{63}$ Los datos básicos de todas estas series han sido los censos nacionales de Busto de 1878 a 1879, Peñafiel de 1895 , y los censos de 1900 y $1910 .{ }^{64}$ Para autores como John Coatsworth y François-Xavier Guerra estas estadísticas, aunque son muy importantes para cualquier estudio cuantitativo de los fenómenos económicos y sociales de la segunda mitad del siglo XIX en México,

${ }^{60}$ Nickel, Peonaje, 1997, p. 153.

${ }^{61}$ Ibid, p. 154.

${ }^{62}$ Valerio, Historia, 2003.

${ }^{63}$ Estadísticas, 1960; González, Estadísticas, 1956; Estadísticas, 1985, vol. I, pp. 153-241.

${ }^{64}$ Guerra, México, 1988, vol. II, p. 473. 
presentan múltiples ambigüedades que hacen muy peligroso su uso, como acabamos de ver con Busto, si no se conocen los criterios en función de los cuales han sido compilados los datos estadísticos. ${ }^{65}$

Guerra destaca que hay problemas esenciales como el de la clasificación de los hombres que vivían en el campo en su relación con la tierra: hacendados, agricultores, peones y jornaleros. En lo que respecta al término de peón y de jornalero usados en los censos mencionados, parece que se borra toda distinción entre las distintas clases de trabajadores rurales que existían en el campo mexicano, como peones acasillados, jornaleros temporales, campesinos con tierras de los pueblos, arrendatarios y medieros, de tal manera que el término de peón se toma para designar a cualquier clase de trabajador agrícola, lo cual finalmente se asocia con el término de peón acasillado ${ }^{66}$ Esta falta de precisión en los conceptos y categorías lleva a estimaciones erróneas por parte de los autores de las Estadísticas económicas del porfiriato, y de otros autores que toman los datos de esta obra, quienes calculan un elevado porcentaje de peones sin tierra y por lo tanto acasillados, los cuales reciben un salario y una ración diaria $y$ de forma permanente. ${ }^{67}$

Por otra parte, el concepto de salario mínimo que manejan las Estadísticas económicas del porfiriato se refiere sólo al pago en moneda a los peones y jornaleros, lo cual, como ya vimos, no incluye todos los ingresos del trabajador, ni mucho menos el valor de los bienes indispensables para vivir éste y su familia. De esta manera, con una información fragmentaria y dispersa, se calculan salarios generales en toda la república y por sectores, entre ellos el de la agricultura, se estiman promedios y se hacen ponderaciones. Luego se comparan con el comportamiento del índice de precios de la ciudad de México, dado que no hubo suficiente información para establecer un índice de precios a escala nacional, pero además, dicho índice se hizo a partir sólo de algunos artículos, pues tampoco se tuvo información suficiente para disponer de un índice que reflejara los precios de todos los artículos. A pesar de todas estas limitantes, los autores de las Estadísticas sostienen que dicho índice es aceptable "si se supone que los precios fluctuaban de manera semejante en la ciudad de México y en el resto del país; o si se supone que el consumo se distribuía (entre los diversos artículos) de manera similar en todo el país". Entre estos y otros supuestos de precios de productos y salarios mínimos, se hace el cálculo de los salarios reales. Según los autores de las Estadísticas, los salarios reales aumentaron durante los primeros 20 años del

\footnotetext{
${ }^{65}$ Coatsworth, Orígenes, 1990, pp. 162-177; Guerra, México, 1988, vol. II, pp. 473-490.

${ }^{66}$ Guerra, México, 1988, vol. II, pp. 175-176.

${ }^{67}$ Ibid., p. 178.
} 
porfiriato, para deteriorarse constantemente entre 1900 y $1910{ }^{68}$ Desafortunadamente, todos estos malabares estadísticos, cálculos, ponderaciones y supuestos implican errores en las estimaciones globales, de tal manera que hacen que las estadísticas sean poco útiles. ${ }^{69}$

Definitivamente, los libros de contabilidad de las haciendas: los rayadores, los estados de la semana, las cuentas de operarios, los libros de caja, los libros de medieros, inventarios, balances y la correspondencia, son las fuentes más importantes y confiables para el análisis de las relaciones laborales y de los salarios en las haciendas mexicanas. ${ }^{70}$ Aunque el problema de este tipo de fuentes es que se refieren única y exclusivamente a la hacienda en cuestión, y de la cual no se pueden desprender mecánicamente conclusiones o aseveraciones generales para otras haciendas de la misma región, ni mucho menos para las haciendas de todo el país, debido a que las haciendas dependían en gran medida del acceso a la mano de obra, de los recursos naturales, principalmente tierra y agua, del acceso a los mercados y a los capitales, según su disponibilidad en determinados contextos locales, regionales nacionales e incluso internacionales. ${ }^{71}$

Para la época colonial se cuenta con los extensos inventarios de documentos de haciendas pertenecientes a la Compañía de Jesús, hasta su expulsión en 1767, y que más tarde fueron explotadas y administradas por una administración fiduciaria del gobierno, denominada Junta de Temporalidades, hasta su subasta. Numerosos de estos documentos se conservan en buenas condiciones y están accesibles en archivos públicos como el Archivo General de la Nación, el Archivo Histórico de la Universidad de Puebla, y otros archivos estatales. ${ }^{72}$

A pesar de que desde la época colonial los hacendados estaban obligados a llevar libros de contabilidad en sus haciendas y fue una práctica común durante todo el siglo XIX en los hacendados mexicanos, sólo ocasionalmente se pueden encontrar estos documentos. Los estudios monográficos que se han hecho a partir de los libros de contabilidad de las haciendas han sido posibles porque las instituciones civiles o religiosas los donaron a los archivos históricos nacionales, estatales o universitarios; o porque las familias herederas de los hacendados coloniales y decimonónicos han conservado bajo su propiedad los libros y han permitido a los historiadores trabajarlos. ${ }^{73}$

${ }^{68}$ Estadísticas, 1960, pp. 9-17.

${ }^{69}$ Guerra, México, 1988, vol. II, p. 473.

${ }^{70}$ Nickel, Peonaje, 1997, p. 121.

${ }^{71}$ Young, Crisis, 1992, p. 139.

${ }^{72}$ Nickel, Peonaje, 1997, p. 121.

${ }^{73}$ Mertens, Atlixco, 1988; Vargas-Lobsinger, Hacienda, 1984; Bazant, Cinco, 1975; Barret, Hacienda, 1977; Leal, Economía, 1982. 
Sin embargo, el problema de este tipo de fuentes es su escasez, su difícil acceso y su falta de continuidad, debido a que rara vez se conservaron los documentos de contabilidad. Para el trabajo y el análisis adecuados de la información de estas fuentes se requieren secuencias de más de 30 o 40 años completos, ya que sólo entonces se pueden elaborar perfiles de ingresos y endeudamientos de trabajadores aislados durante la totalidad del periodo laboral, y se puede analizar la dependencia de su endeudamiento de variables internas y externas de la hacienda. Para la determinación del salario real en determinadas haciendas, se requieren datos correspondientemente largos, pero además compararlos con la información de salarios y precios en el ámbito local y regional. ${ }^{74}$

La mayoría de los libros de contabilidad de las haciendas han sido destruidos debido principalmente al desinterés de los propietarios por la antigua contabilidad, principalmente porque los libros ocupaban bastante espacio y significaban una carga y un costo, del cual los descendientes de las familias de terratenientes se deshacían con gusto al vender la propiedad o posteriormente al no encontrar en ellos ningún valor o ninguna utilidad. Por el contrario, los hacendados estuvieron más interesados en conservar documentos de mayor importancia como los títulos de propiedad, los convenios de arrendamiento y las deudas hipotecarias, y aquellos documentos que les pudieran ser útiles para demostrar el abolengo y el estatus social de la familia. ${ }^{75}$

La prensa mexicana de la segunda mitad del siglo XIX y principios del $\mathrm{xx}$, incluyendo las revistas especializadas, es una fuente muy importante para el estudio de las relaciones laborales en el campo mexicano. En ella se publicaba información sobre las grandes haciendas, la cual permitía formarse una cierta idea del funcionamiento de las mismas, pero se preocupaban más por la introducción de innovaciones técnicas y nuevos productos de cultivo; por publicar los precios de los productos agrícolas en los mercados nacionales y regionales, así como en las principales ciudades del país, la publicación de los decretos importantes para los hacendados, y sólo en una mínima proporción se referían a las condiciones de vida de los trabajadores agrícolas y a los conflictos laborales en las haciendas. Sólo la prensa crítica, que en realidad era una minoría del total de publicaciones, se ocupó de los trabajadores rurales hablando en su defensa, sin embargo, el nivel de análisis de este tipo de prensa no rebasaba el tono apologético e ideológico de los discursos políticos radicales, carecía de la información estadística confiable para desarrollar un análisis más serio y profesional. Por tal motivo, la prensa decimonónica

${ }_{75}$ Nickel, Peonaje, 1997, p. 140.

${ }^{75}$ Ibid., p. 142. 
sirve más como fuente para el análisis de los distintos discursos y posiciones políticas e ideológicas con respecto a los problemas del campo mexicano, que como fuente de información estadística confiable de los procesos económicos y sociales del mismo. ${ }^{76}$

\section{CONCLUSIONES}

Como hemos visto, la falta de claridad y continuidad en las fuentes documentales, además de su escasez, hace casi imposible un análisis cuantitativo y estadístico de los salarios a largo plazo, sobre todo en términos de valor y del nivel de vida de los trabajadores agrícolas, ya que no hay un parámetro válido y homogéneo de comparación entre los salarios de antes y de ahora. Por lo mismo no se puede estimar la productividad marginal del trabajo ni de la tierra, ni se puede estimar claramente la relación de precios y salarios en mercados tan imperfectos como los del campo mexicano de los siglos XVI al XIX. Hace falta construir series estadísticas de precios y de salarios más confiables, cuando las fuentes documentales lo permitan, sobre todo en el mediano y en el corto plazo, desde el plano microeconómico de una empresa hasta el plano nacional, pasando por el ámbito local y regional, de tal manera que reflejen mejor las condiciones económicas y sociales de los trabajadores rurales en México a lo largo de su historia.

\section{BIBLIOGRAFÍA}

BARRet, WARD, La hacienda azucarera de los marqueses del Valle, México, Siglo XXI, 1977. BAZANT, JaN, Cinco haciendas mexicanas: tres siglos de vida rural en San Luis Potosí, 16001910, México, CEH-COLMEX, 1975.

BoraH, WoOdrow, El siglo de la depresión en Nueva España, México, Era, 1982.

Braudel, Fernand, La historia y las ciencias sociales, México, Alianza, 1989.

Carrasco, Pedro, "La economía del México prehispánico" en Pedro Carrasco y

Johanna Broda (ed.), Economía política e ideológica en el México prehispánico, México, Nueva Imagen, 2a. ed., 1980, pp. 13-76.

COATSWORTH, John H., Los orígenes del atraso. Nueve ensayos de historia económica de México en los siglos XVIII y XIX, México, Alianza, 1990.

Dobb, MaUrice, Salarios, México, FCE, 2a. ed., 1941.

Teorias del valor y de la distribución desde Adam Smith. Ideología y teoría económica, México, Siglo XXI, 6a. ed., 1982.

${ }^{76}$ Ibid., pp. 160-161. 
Estadísticas económicas del porfiriato: fuerza de trabajo y actividades por sectores, México, ColmeX, 1960 ( $i 1961$ ?).

Estadísticas históricas de México, México, INEGI, 1985, 2 vols.

FLORESCANO, ENRIQUe, Origen y desarrollo de los problemas agrarios de México, 1500-1821, México, Era/sEP, 1986.

Gibson, Charles, Los aztecas bajo el dominio español, 1579-1810, México, Siglo XXI, 6 a. ed., 1981.

GonzÁlez NAVARro, Moisés, Estadísticas sociales del porfiriato, 1877-1910, México, ColmeX, 1956. , Repartimientos de indios en Nueva Galicia, México, INAH, 1977.

Guerra, François-Xavier, México: del antiguo régimen a la revolución, México, FCE, 1988,2 vols.

KATZ, FRIEDRICH, La servidumbre agraria en México en la época porfiriana, México, Era, 2a. ed., 1982.

Leal, Juan Felipe y Mario Huacuja Rountree, Economía y sistema de haciendas en México. La hacienda pulquera en el cambio, siglos XVIII, XIX y XX, México, Era, 1982.

López Austin, Alfredo y LeONARdo López LujÁN, El pasado indígena, México, FCE, 2001. MARX, KarL, El capital, México, Siglo XXI, 1975. , Introducción general a la crítica de la economía política (1857), México, Siglo XXI, 14a. ed., 1980.

Mertens, Hans GüntHer, Atlixco y las haciendas durante el porfiriato, Puebla, Universidad Autónoma de Puebla, 1988.

Molina EnRÍQuez, ANDrÉs, Los grandes problemas nacionales (1909), México, Era, 5a. ed., 1985.

Moreno Toscano, Alejandra. "El siglo de la conquista" en Historia general de México, México, Colmex, 1977, vol. 2, pp. 3-81.

NiCKEL, HERBERT J., El peonaje en las haciendas mexicanas. Interpretaciones, fuentes, hallazgos, México, Universidad Iberoamericana, 1997.

Ricardo, DaVId, Principios de economía política y tributación, México, FCE, 1959.

Schumpeter, Joseph A., Teoría del desenvolvimiento económico, México, FCE, 1944.

SMITH, ADAM, Investigación sobre la naturaleza y causas de la riqueza de las naciones, MéxiCO, FCE, 1958.

VAlERIO UlloA, SERgio, Historia rural jalisciense. Economía agrícola e innovación tecnológica durante el siglo XIX, Guadalajara, Universidad de Guadalajara, 2003.

VARgAS-LOBSINGER, MARÍA, La hacienda de "La Concha". Una empresa algodonera de La Laguna, 1883-1917, México, UNAM, 1984.

Velasco Ávila, Cuauhtémoc et al., Estado y minería en México (1767-1910), México, FCE, 1988.

YOUNG, ERIC VAN, La crisis del orden colonial. Estructura y rebeliones populares de la Nueva España, 1750-1821, México, Alianza, 1992.

Zavala, Silvio y María Castelo, Fuentes para la historia del trabajo en Nueva España, 1939,8 vols. 